\title{
Prevalence and Associated Factors of Anemia Among Pregnant Women Residing at High Altitude in Yemen
}

\author{
Mohammed Yahya M. Akabat, ${ }^{1, ~}$, Abdulqawi Ali Al-Shammakh², Amat Al-Khaleq Obad Mehrass ${ }^{1}$, \\ Abdulelah Hussien Al-Adhroey ${ }^{3}$, Abdullatif Daiffallah Ali ${ }^{2}$ \\ ${ }^{1}$ Department of Gynaecology and Obstetrics, Faculty of Medicine and Health Sciences, Thamar University, Dhamar, Yemen \\ ${ }^{2}$ Department of Biochemistry, Faculty of Medicine and Health Sciences, Thamar University, Dhamar, Yemen \\ ${ }^{3}$ Department of Community Medicine, Faculty of Medicine and Health Sciences, Thamar University, Dhamar, Yemen
}

Email address:

m_y_akabat@hotmail.com (M. Y. M. Akabat), aqawi54@gmail.com (A. A. Al-Shammakh). amatmehrass@gmail.com (A. Al-Khaleq O. M.), husssien75@gmail.com (A. H. Al-Adhroey), abdullatifwhite@gmail.com (A. D. Ali)

*Corresponding author

\section{To cite this article:}

Mohammed Yahya M. Akabat, Abdulqawi Ali Al-Shammakh, Amat Al-Khaleq Obad Mehrass, Abdulelah Hussien Al-Adhroey, Abdullatif Daiffallah Ali. Prevalence and Associated Factors of Anemia Among Pregnant Women Residing at High Altitude in Yemen. American Journal of Health Research. Vol. 5, No. 4, 2017, pp. 93-98. doi: 10.11648/j.ajhr.20170504.11

Received: May 4, 2017; Accepted: May 10, 2017; Published: July 6, 2017

\begin{abstract}
Anemia continues to be a major health problem affecting the mother and her neonate in the developing countries. The present study was aimed to investigate the prevalence and risk factors of anemia among Yemeni pregnant women residing in Dhamar district 2400 meters above the sea level. This was a cross-sectional study aimed to investigate the prevalence and risk factors of anemia among Yemeni pregnant women residing in Dhamar district, 2400 meters above the sea level. A total of 420 pregnant women visiting the general Maternal and Child Center for antenatal care were randomly selected. A hemoglobin cutoff value of $12.3 \mathrm{~g} / \mathrm{dl}$ was used for evaluating the prevalence of anemia, according to the recommendations of World Health Organization pertaining on altitude adjusted hemoglobin concentrations. The results found that the overall prevalence of anemia among the study population was $26.56 \%$. Moderate-to-severe anemia accounted for almost one-quarter of the disease burden. Trimester of pregnancy and number of cesarean surgeries were retained by multivariate regression model as significant risk factors. Over first trimester, the prevalence risk for predicting anemia was more significantly associated with third trimester $(\mathrm{APR}=3.00 ; 95 \% \mathrm{CI}=1.82,4.94 ; \mathrm{P}=0.000)$ rather than second trimester of pregnancy $(\mathrm{APR}=1.73 ; 95 \% \mathrm{CI}=1.01,2.96 ; \mathrm{P}=$ $0.047)$. The pregnant women undergone two or more cesarean surgeries were significantly at higher risk for anemia $(A P R=1.63$; $95 \% \mathrm{CI}=1.12,2.38 ; \mathrm{P}=0.012$ ). The present study revealed that anemia is still a public health problem among the pregnant women in Yemen. There is a need for intervening and controlling this jeopardy using effective programs and strategies.
\end{abstract}

Keywords: Anemia, Prevalence, Pregnancy, High Altitude, Yemen

\section{Introduction}

Anemia is a pathological condition in which the number of red blood cells or concentration of hemoglobin $(\mathrm{Hb})$ is inadequate to cover all the physiological requirements for the human body. Its global burden is still enormous affecting all age groups of people, and it results in more than two billion cases worldwide with the highest prevalence among pregnant women and children [1-2].

In pregnant women, anemia is associated with short and long term negative health consequences. It affects the health and productivity of mothers, children, and community. Recent estimates suggest that anemia during pregnancy causes about 700,000 deaths worldwide annually [3]. The association of anemia with growth retardation and poor cognitive function of children, and work productivity are well documented [4-5]. These negative consequences may continue to affect the development of the country and cause low work and economy productivities which trap the community at risk of diseases in a circle of poverty and collapsed health facilities [6-7].

In the developing countries with low socioeconomic status, pregnant women suffer most from the adverse health 
consequences of anemia in which the risk factors could be nutritional, clinical, and demographic factors. They are more prone to be affected with macro and micronutrient deficiencies, heavy menstruation, and blood loss associated with delivery, general inflammatory disorders, and infections [8].

The Republic of Yemen is one of the poorest and least developed countries in the world. It ranks 160 out of 188 countries in 2015 [9]. An estimated $42 \%$ of the people are poor, and $80 \%$ of the country's poor people live in rural areas and most of them depend on agriculture for their livelihoods [10]. Maternal mortality in Yemen are the highest among the Middle East Countries being 370 per 100,000 live births [11]. Furthermore, $25 \%$ of women are estimated to be malnourished [12]. Although the prevalence of anemia among pregnant women in Yemen has not yet been well documented nationwide, limited data indicates that prevalence of this burden among pregnant women [13]. Therefore this study aims to estimate the prevalence and associated factors of anemia among Yemeni pregnant women in Dhamar district using altitude adjusted hemoglobin cutoff.

\section{Methodology}

\subsection{Study Area and Study Population}

The study was performed in Dhamar district, which is one of 12 districts belonging to Dhamar governorate, Yemen. Dhamar district is located $100 \mathrm{~km}$ to the south of the capital Sana'a. The altitude is about 2400 meter above sea level with population of 173,000 in 2004 [14]. The district is enclosed the general Maternal and Child Center, which is the main maternity facility in Dhamar city and accessible to women from most part of the districts.

The sample size was determined based on single population proportion formula, with a $95 \%$ CI, $5 \%$ absolute Poisson and assuming that $30 \%$ of pregnant women are anemic. Pregnant women were randomly selected from RHC and total of 420 were successfully enrolled in this study.

\subsection{Study Design}

This was a cross- section study designed to assess the prevalence and associated risk factors of anemia among pregnant women attending antenatal or medical clinics at the general Maternal and Child Center in Dhamar district, Yemen, between December 2014 and June 2015.

The study design was planned with a $95 \%$ confidence level and 0.50 expected frequency. Data were collected using pretested questionnaire, which contains sociodemographic characteristics (age, residence, education, occupation household income and other), obstetric and gynecological history (trimester, gravidity, number of living children, number of cesarean surgery and others), and dietary habits (intake of meat, fruits, and using iron supplementation).

Anemia during pregnancy and the degree of anemia was defined according to the World Health Organization (WHO) criteria [1]. Altitude adjustments of $\mathrm{Hb}(1.3 \mathrm{~g} / \mathrm{dl})$ for altitude 2400 meter was used to develop the cutoff of anemia and the severity of anemia based on the WHO report on $\mathrm{Hb}$ concentration for the diagnosis of anemia and assessment of severity [1]. A pregnant woman with $\mathrm{Hb}$ less than $12.3 \mathrm{~g} / \mathrm{dl}$ is considered anemic. The degree of anemia was determined as mild $(\mathrm{Hb}=10.3-12.2 \mathrm{~g} / \mathrm{dl})$, moderate $(\mathrm{Hb}=8.3-10.2 \mathrm{~g} / \mathrm{dl})$ and severe anemia $(\mathrm{Hb}<8.3 \mathrm{~g} / \mathrm{dl})$.

Exclusion criteria was including those who are too sick, cases of dysfunctional uterine bleeding, any other diagnosed diseases especially hemoglobinopaties, renal and liver disease, history of multiple pregnancy and those not willing to participate in the study.

An ethical committee approval has been obtained for the study protocol. Informed consents were obtained from the respondents prior to the data collection.

\subsection{Sample Collection and Processing}

Blood sample was collected from each pregnant woman after completing the interview by trained laboratory nurses. $\mathrm{Hb}$ was detected using Beckman Coulter AcT 3 diff haematology analyzer from Beckman Coulter (Fullerton, CA, USA) [15].

\subsection{Data Analysis}

Data were analyzed using Statistical Package for Social Science (SPSS) version 23. Anemia $(\mathrm{Hb}<12.3 \mathrm{~g} / \mathrm{dl})$ was analyzed as the dependent factor dichotomously $(0=\mathrm{Hb} \geq$ $12.3 \mathrm{~g} / \mathrm{dl}, 1=<\mathrm{Hb} 12.3 \mathrm{~g} / \mathrm{dl}$ ). The potential risk factor of anemia were age, age at marriage, residence, education, family income, dietary habits trimesters, gravidity, number of living children and number of cesarean surgeries. The prevalence ratio (PR) of anemia was developed using Poisson regression analysis [16]. Univariate analysis was used to assess the association of the potential risk factors with anemia. Potential factors that showed an association with anemia at a $\mathrm{P}$ value of $\leq 0.2$ was used to adjust the multivariate model. The adjusted PR was then calculated. This study used a P value of $\leq 0.05$ as the level of significance.

\section{Results}

\subsection{Socio-demographic Characteristics of the Participants}

Table 1. Socio-demographic characteristics of pregnant women in Dhamar district, Yemen $(N o=420)$.

\begin{tabular}{ll}
\hline Characteristics & Frequency $(\%)$ \\
\hline Maternal age & \\
$16-24$ & $210(50.0)$ \\
$25-34$ & $168(40.0)$ \\
$\geq 35$ & $42(10.0)$ \\
BMI $\left(\mathrm{kg} / \mathrm{m}^{2}\right)$ & \\
$\leq 24.9$ & $264(62.9)$ \\
$>25$ & $156(37.1)$ \\
Age at marriage & \\
$\leq 15$ & $86(20.5)$ \\
$>15$ & $334(79.5)$ \\
Residence & \\
Urban & $238(56.7)$ \\
Rural & $182(43.3)$ \\
\hline
\end{tabular}




\begin{tabular}{ll}
\hline Characteristics & Frequency (\%) \\
\hline Education & $178(42.6)$ \\
$\geq 6$ years formal education & $240(57.4)$ \\
$\begin{array}{l}\text { No formal education } \\
\text { Occupation }\end{array}$ & $13(3.1)$ \\
$\begin{array}{l}\text { Government employee } \\
\text { Housewife }\end{array}$ & $407(96.9)$ \\
Household income & \\
$\geq$ USD 200/month & $137(32.6)$ \\
$<$ USD 200/month & $283(67.4)$ \\
\hline
\end{tabular}

As shown in Table 1, 420 pregnant women participated in this survey. About $50 \%$ of them were in the age 16-24. The majority of the pregnant women were housewives $(96.9 \%)$, and most of them were urban $(56.7 \%)$, with no formal education $(57.4 \%)$. On the other hand most of the participated were with house hold income less than 200USD (67.4\%).

\subsection{Obstetric Characteristics of the Participants}

The obstetric characteristics of pregnant women are revealed in Table 2. Of the 418 participants, 114 (27.3\%) were reported to be in the first trimester, $162(38.7 \%)$ in the second trimester, and $142(34 \%)$ in the third trimester. One third of the respondent had no living children, $50 \%$ had less than four children, and $11 \%$ had five or more at the time of study. Half of the pregnant women $204(48.8 \%)$ said they had one to two antenatal care visits during the present pregnancy. Multi caesarean surgery were reported in $57(13.6 \%)$ of the participants.

Table 2. Obstetric characteristics of pregnant women $($ No $=420)$.

\begin{tabular}{ll}
\hline Characteristics & Frequency (\%) \\
\hline Trimester of pregnancy & $114(27.3)$ \\
First trimester & $162(38.7)$ \\
Second trimester & $142(34.0)$ \\
Third trimester & \\
Gravidity & $107(25.5)$ \\
Primigravidae & $313(74.5)$ \\
Multigravidae & \\
Number of living children & $129(30.7)$ \\
Nil & $155(36.9)$ \\
$1-2$ & $90(21.4)$ \\
$3-4$ & $46(11.0)$ \\
$\geq 5$ & \\
ANC frequency during current pregnancy & $204(48.8)$ \\
$1-2$ & $147(35.2)$ \\
$3-4$ & $67(16.0)$ \\
$\geq 5$ & \\
Number of cesarean surgery & $363(86.4)$ \\
$0-1$ & $57(13.6)$ \\
\hline 2
\end{tabular}

\subsection{Dietary Habits of Pregnant Women}

The dietary habits and iron supplementation are shown in Table 3. Daily eating of meat and fruits were only reported between $15 \%$ and $26 \%$ of the participants. However half of the participants eat vegetable every day. Of 420 pregnant women $60.5 \%$ of them were using Iron supplementation on the time of this study. Majority of the participants were not reporting to be a physically active.
Table 3. Dietary habits of pregnant women $($ No $=420)$.

\begin{tabular}{ll}
\hline Characteristics & Frequency (\%) \\
\hline Eating meats every day & $63(15.0)$ \\
Yes & $357(85.0)$ \\
No & \\
Eating fruits every day & $110(26.2)$ \\
Yes & $310(73.8)$ \\
No & \\
Eating vegetables every day & $211(50.2)$ \\
Yes & $209(49.8)$ \\
No & \\
Using iron supplementation & $254(60.5)$ \\
Yes & $166(39.5)$ \\
No & \\
Physical work & $97(23.1)$ \\
Yes & $323(76.9)$ \\
No &
\end{tabular}

\subsection{Prevalence and Degree of Anemia Among Pregnant} Women

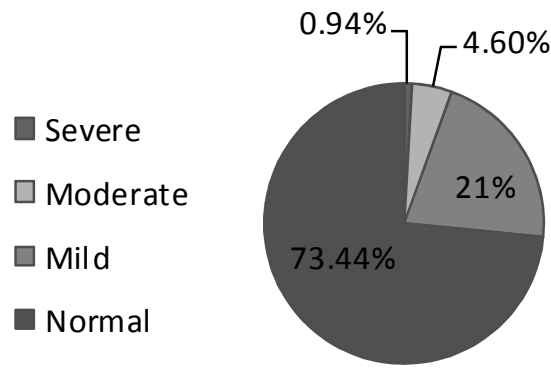

Figure 1. Prevalence and degree of anemia among pregnant women.

Prevalence and degree of anemia among pregnant women is shown in Figure 1. Among the 420 study participants, the overall prevalence of anemia $(\mathrm{Hb}<12.3 \mathrm{~g} / \mathrm{dl})$, was estimated to be $26.56 \%$. The degree of anemia among pregnant women was estimated based on the classification of WHO for the severity and degree of anemia in pregnancy plus the altitude adjusted value $1.3 \mathrm{~g} / \mathrm{dl}$ : mild anemia $(\mathrm{Hb}=10.3-12.2 \mathrm{~g} / \mathrm{dl})$, moderate anemia $(\mathrm{Hb}=8.3-10.2 \mathrm{~g} / \mathrm{dl})$, and severe anemia $(\mathrm{Hb}$ $<8.3 \mathrm{~g} / \mathrm{dl}$ ). The result of this study indicated $21 \%$ mild anemia, $4.6 \%$ moderate anemia, and $0.94 \%$ severe anemia among pregnant women.

\subsection{Factors Associated with Anemia Among Pregnant Women}

The association of relevant variables with anemia is presented in Table 4. Univariate analysis indicated that the third trimester $(\mathrm{PR}=3.05 ; 95 \% \mathrm{CI}=1.83,5.09 ; \mathrm{P}=0.000)$, the second trimester $(\mathrm{PR}=1.83 ; 95 \% \mathrm{CI}=1.06,3.16 ; \mathrm{P}=0.030)$, the cesarean surgery $\geq 2 \mathrm{PR}=1.56 ; 95 \% \mathrm{CI}=1.07,2.26 ; \mathrm{P}=$ $0.020)$ and those were not used to eat fruits $(\mathrm{PR}=1.54 ; 95 \%$ $\mathrm{CI}=1.01,2.34 ; \mathrm{P}=0.046)$ and vegetables every day $(\mathrm{PR}=$ $1.50 ; 95 \% \mathrm{CI}=1.09,2.08 ; \mathrm{P}=0.014$ ) showed association with the prevalence of anemia. Logistic regression analysis confirmed that third trimester $(\mathrm{APR}=3.00 ; 95 \% \mathrm{CI}=1.82$, 4.94; $\mathrm{P}=0.000)$, second trimester $(\mathrm{APR}=1.73 ; 95 \% \mathrm{CI}=1.01$, $2.96 ; \mathrm{P}=0.047)$, and cesarean surgery $\geq 2(\mathrm{APR}=1.63 ; 95 \%$ $\mathrm{CI}=1.12,2.38 ; \mathrm{P}=0.012$ ) were significant risk factors for prevalence of anemia among pregnant women in this study. 
Table 4. Factors associated with anemia among pregnant women in Dhamar district, Yemen (No $=420)$.

\begin{tabular}{|c|c|c|c|c|}
\hline \multirow{2}{*}{ Variables } & \multicolumn{4}{|c|}{ Anemia $(\mathrm{Hb}<12.3 \mathrm{~g} / \mathrm{dl})$} \\
\hline & Prevalence (\%) & PR (95\% CI) & APR $(95 \%$ CI) & $P$ \\
\hline \multicolumn{5}{|l|}{ Age at marriage } \\
\hline$\leq 15$ & $86(20.5)$ & $0.95(0.64,1.42)$ & & 0.800 \\
\hline$>15$ & $334(79.5)$ & 1 & & \\
\hline \multicolumn{5}{|l|}{ Maternal age* } \\
\hline$\geq 35$ & 35.7 & $1.39(0.87,2.21)$ & $1.10(0.60,2.08)$ & $0.167,0.775$ \\
\hline $25-34$ & 25.6 & $0.96(0.71,1.41)$ & $0.92(0.60,1.40)$ & $0.979,0.599$ \\
\hline $16-24$ & 25.7 & 1 & 1 & \\
\hline \multicolumn{5}{|l|}{ Residence } \\
\hline Rural & 43.3 & $1.13(0.83,1.56)$ & & 0.439 \\
\hline Urban & 46.7 & 1 & & \\
\hline \multicolumn{5}{|l|}{ Education* } \\
\hline No formal education & 29.6 & $1.28(0.92,1.80)$ & $1.09(0.79,1.52)$ & $0.140,0.599$ \\
\hline$\geq 6$ years formal education & 23.0 & 1 & & \\
\hline \multicolumn{5}{|l|}{ Household income* } \\
\hline$<$ USD $200 /$ month & 29.7 & $1.45(1.00,2.12)$ & $1.34(0.92,1.94)$ & $0.052,0.125$ \\
\hline$\geq$ USD $200 /$ month & 20.4 & 1 & & \\
\hline \multicolumn{5}{|l|}{ Trimester of pregnancy** } \\
\hline Third trimester & 40.1 & $3.05(1.83,5.09)$ & $3.00(1.82,4.94)$ & $<0.001,<0.001$ \\
\hline Second trimester & 24.1 & $1.83(1.06,3.16)$ & $1.73(1.01,2.96)$ & $0.030,0.047$ \\
\hline First trimester & 13.2 & 1 & & \\
\hline \multicolumn{5}{|l|}{ Number of living children* } \\
\hline$\geq 5$ & 34.8 & $1.48(0.88,2.39)$ & $1.00(0.52,1.90)$ & $0.148,0.989$ \\
\hline $3-4$ & 27.8 & $1.16(0.72,1.2)$ & $1.22(0.65,1.94)$ & $0.531,0.680$ \\
\hline $1-2$ & 25.8 & $1.07(0.72,1.61)$ & $0.96(0.64,1.45)$ & $0.731,0.859$ \\
\hline Nil & 24.0 & 1 & & \\
\hline \multicolumn{5}{|l|}{ Gravidity } \\
\hline Multigravidae & 74.5) & $1.13(0.77,1.65)$ & & 0.526 \\
\hline Primigravidae & 107 & 1 & & \\
\hline \multicolumn{5}{|c|}{ Number of cesarean surgery** } \\
\hline$\geq 2$ & 38.6 & $1.56(1.07,2.26)$ & $1.63(1.12,2.38)$ & $0.020,0.012$ \\
\hline $0-1$ & 24.8 & 1 & & \\
\hline \multicolumn{5}{|l|}{ Eating meat every day } \\
\hline No & 85 & $1.06(0.67,1.67)$ & & 0.806 \\
\hline Yes & 15 & 1 & & \\
\hline \multicolumn{5}{|l|}{ Eating fruits every day* } \\
\hline No & 29.4 & $1.54(1.01,2.34)$ & $1.22(0.72,1.74)$ & $0.046,0.617$ \\
\hline Yes & 19.1 & 1 & & \\
\hline \multicolumn{5}{|l|}{ Eating vegetables every day** } \\
\hline No & 32.1 & $1.50(1.09,2.08)$ & $1.40(.99,1.99)$ & $0.014,0.057$ \\
\hline Yes & 21.3 & 1 & & \\
\hline \multicolumn{5}{|l|}{ Using iron supplementation } \\
\hline No & 39.5 & $1.15(0.83,1.61)$ & & 0.402 \\
\hline Yes & 60.5 & 1 & & \\
\hline
\end{tabular}

PR: prevalence ratio; $A P R$ : adjusted prevalence ratio; $\mathrm{CI}$ : confidence interval; P: level of significance

*Potential association $(\mathrm{P} \leq 0.20),{ }^{* *}$ Significant association $(\mathrm{P}<0.05)$

\section{Discussion}

This the first study to reveal the prevalence of anemia among pregnant women in Dhamar district Yemen, using a cutoff level of $\mathrm{Hb}<12.3 \mathrm{~g} / \mathrm{dl}$. Gratification for using the $\mathrm{Hb}$ level $<12.3 \mathrm{~g} / \mathrm{dl}$ as a cutoff for anemia in the study's subjects was based on the relation between $\mathrm{Hb}$ concentration and altitude oxygen concentration. Following the WHO recommendation [1], this study adjusted the cutoffs by adding $1.3 \mathrm{~g} / \mathrm{dL}$ for the altitude of 2400 meter.

The overall prevalence of anemia among pregnant women involved in this study is $26.56 \%$. This prevalence according to WHO classification of the public health importance of anemia is a moderate public health problem [17]. The prevalence shown in this study was comparable with the results reported from neighboring countries which indicated that prevalence of anemia among pregnant women in Oman 34\%, Qatar $28 \%$, Syrian Arab Republic 30\%, Iraq 31\%, Jordan 27\%,\%, Lebanon 27\%, Libya 28\%, United Arab Emirates 26\%, Ethiopia 23\%, Sri Lanka 26\% and Iran, Islamic Rep 26\% [13, 17]. On the other hand, the prevalence of anemia in the present study was lower than that reported in Tanzania (58.2\%), Yemen (58.09\%), Sudan (57.745), Guinea-Bissau (57.7\%), 
Senegal (57.58\%), Vanuatu (57.3\%), Cambodia (57.1\%) and Angola (57.07\%) [13].

The present study specifies that out of all pregnant women involved in this study $21 \%$ had mild anemia, $4.6 \%$ had moderate anemia, and $0.94 \%$ had severe anemia. These findings are also similar to the findings from other studies [18-20].

Anemia occurs at all stages of the life cycle but its risk is higher in state of pregnancy. Anemia in pregnancy is related to different socio-demographic factors. In different studies, age, educational status, economic position, gravidity, miscarriage and gestational age were the major risk factors for anemia in pregnancy [21-22]. Investigating the possible risk factors associated with anemia among the participants revealed that trimesters were important variables, which have shown a significant association with anemia. The risk of developing anemia was higher in third and second trimester. This finding is consistent with a study conducted in Saudi Arabia, India and Malaysia [23-25]. This could be explained by the fact that there is an increase in hemodilution as a result of increase in estrogen level towards the end of gestational age [26]. Furthermore physiological requirements for iron in pregnancy are three times higher than in non-pregnant menstruating women and iron requirement increases as pregnancy advances. In addition to Iron $20 \%$ of women show a physiological drop in vitamin B12 levels during pregnancy, with lowest levels reached at third trimester [27].

Pregnant women who underwent two or more cesarean surgeries were found to have an increased risk of anemia during the present pregnancy. In fact cesarean sections are not without complications and consequences. A study in three London hospitals revealed that women who have caesarean sections run a 4-fold risk of suffering serious complications, including hemorrhage, infection and rupture of the uterus [28]. Retrospective review of almost 1000 cesareans, estimated blood loss of greater than $1000 \mathrm{ml}$ was recorded in $9.2 \%$ of cesarean births, with $1 \%$ of women requiring a blood transfusion [29]. Bleeding during cesarean surgery leads to depletion of iron stores and reduction of erythropoiesis and therefore the $\mathrm{Hb}$ level falls.

\section{Conclusions}

This is the first cross-section study carried out among Yemeni pregnant women in Dhamar district. The prevalence of anemia among the study population is found to be $26.7 \%$. Trimester of current pregnancy and multiple cesarean deliveries associated significantly with the disease. Using effective programs and strategies is imperative for improving the maternal health in this poor community. Further large national survey is recommended to estimate the magnitude of this public problem and to ascertain the causes and predisposing factors.

\section{Acknowledgment}

The authors are grateful to the management and staff of the general Maternal and Child Center in Dhamar district, Miss
Mariam Al-Sanabani, Dr. Amat AL-Qader AL - a'anesi and the nurses of the prenatal and medical clinics for their advices and support during the survey. The authors are thankful for the fourth-year students of Medical Laboratories Sciences (Academic year 2013/2014) and for their help in the collection of the study data. The authors gratefully acknowledge the participants of this study for their collaboration. The financial supported of Thamar University Faculty of Medicine and Health Sciences is gratefully acknowledged.

\section{References}

[1] World Health Organization (WHO). Hemoglobin Concentrations for the Diagnosis of Anaemia and Assessment of Severity, Vitamin and Mineral Nutrition Information System. Geneva, Switzerland: WHO, 2011.

[2] Y. Balarajan, U. Ramakrishnan, E. Ozaltin, A. H. Shankar, S. V. Subramanian, 'Anaemia in low-income and middle-income countries', The Lancet, vol. 378, pp. 2123-2135, 2011.

[3] S. Salhan, V. Tripathi, R. Singh, Gaikwad H S. "Evaluation of hematological parameters in partial exchange and packed cell transfusion in treatment of severe anemia in pregnancy", Anemia, vol. 2012, doi: 10.1155/2012/608658.

[4] R. J. Stoltzfus, "Iron deficiency: Global prevalence and consequences", Food Nutr Bull, vol. 24, S99-103, 2003.

[5] J. S. Halterman, J. M. Kaczorowski, A. C. Aligne, P. Auinger, P G. Szilagyi, "Iron deficiency and cognitive achievement among school-aged children and adolescents in the United States", Pediatrics, vol. 107, pp. 1381-1386, 2001.

[6] J. D. Haas, T. Brownlie, "Iron deficiency and reduced work capacity: a critical review of the research to determine a casual relationship', J Nutr, vol. 131, pp. 676S-690S, 2001.

[7] H. Bleakley, "Disease and development: evidence from hookworm eradication in the American South", Quarterly Journal of Economics, vol. 122, pp. 73-117, 2007.

[8] World Health Organization (WHO). Worldwide prevalence of anaemia 1993-2005: WHO global database on anaemia, Geneva, Switzerland: WHO, 2008.

[9] Human Development Report. United Nations Development Programme (UNDP). 2015; page 49.1 UN Plaza, New York, NY 10017, USA. E. 15. III. B. 1 ISBN: 978-92-1-126398-5 eISBN: 978-92-1-057615-4 ISSN: 0969-4501.

[10] Rural poverty in Yemen - Rural Poverty Portal https://www. ruralpovertyportal.org/web/rural-poverty-portal/country/home/ tags/yemen.

[11] A. M. Makki, "Risk factors for low birth weight in Sana'a City, Yemen", Ann Saudi Med, vol. 22, pp. 333-335, 2002.

[12] Data of the survey conducted by Nutrition Department, MOPHP, and JICA, 2008.

[13] G. A. Stevens, M. M. Finucane, L. M. De-Regil, et al., "Global, regional, and national trends in hemoglobin concentration and prevalence of total and severe anaemia in children and pregnant and non-pregnant women for 1995-2011: a systematic analysis of population-representative data", The Lancet Global Health, 2013, doi: 10.1016/S2214-109X(13)70001-9. 
[14] Central Statistical Organisation, Republic of Yemen. 2004; Retrieved from (https://www.citypopulation.de/Yemen.html).

[15] H. I. Biambo. O. A. Ejele, C. A. Nwauche, "An evaluation of the Beckman-Coulter AcT 3-part differential haematology analyzer in a tertiary hospital laboratory", Niger J Med, vol. 14, pp. 183-187, 2005.

[16] Bru B. Simeon-Denis Poisson. In ' Statisticians of the Centuries, ed. C. C. Heyde and E. Seneta. 2001; 123-6. New York: Springer.

[17] World Health Organization (WHO). The global prevalence of anaemia in 2011. Geneva Switzerland: WHO, 2015.

[18] M. Mulugeta, A. Zelalem, A. Meseret, E. Bamlaku, "Prevalence and Predictors of Maternal Anemia during Pregnancy in Gondar, Northwest Ethiopia: An Institutional Based Cross-Sectional Study", Anemia, vol. 2014, 2014. PMC3942101.

[19] E. I. Ugwuja, E. I. Akubugwo, U. A. Ibiam, O. Onyechi, "Impact of maternal iron deficiency and anaemia on pregnancy and its outcomes in a Nigerian population", The Internet Journal of Nutrition and Wellness, vol. 10, pp. 1-11, 2010.

[20] C. Aluka, A. N. Amadi, C. I. Kamamu, P. A. Feiyi Waboso, "Anaemia in pregnancy in Abia State University teaching hospital, Aba", Journal of Medical Investigation and Practice, vol. 2, pp. 58-61, 2001.

[21] J. A. Noronha, A. Bhaduri, H. Vinod Bhat, A. Kamath, "Maternal risk factors and anaemia in pregnancy: a prospective retrospective cohort study", J Obstet Gynaecol, vol. 30, pp. 132- 136, 2010.

[22] A. H. Jufar, T. Zewde, "Prevalence of Anemia among Pregnant
Women Attending Antenatal Care at Tikur Anbessa Specialized Hospital, Addis Ababa Ethiopia", J Hematol Thromb Dis, 2014, doi: 10.4172/2329-8790.1000125.

[23] S. S. Elzahrani, "Prevalence of iron deficiency anemia among pregnant women attending antenatal clinics at Al-Hada Hospital', Canadian Journal on Medicine, vol. 3, pp. 10-14, 2012.

[24] R. G. Vivek, A. B. Halappanavar, P. R. Vivek, S. B. Halki, V. S. Maled, P. S. Deshpande, "Prevalence of Anemia and its epidemiological", Determinants in Pregnant Women, vol. 5, pp. 216-223, 2012.

[25] R. Aikawa, N. C. Khan, S. Sasaki, C. W. Binns, "Risk factors for iron-deficiency anaemia among pregnant women living in rural Vietnam", Public Health Nutrition, vol. 9, pp. 443-448, 2006.

[26] T. Susan, D. O. Blackburn, "Maternal, Fetal, \& Neonatal Physiology: A Clinical Perspective", Qualitative Health Research, vol. 11, pp. 780- 794, 2007.

[27] N. Milman, K. E. Byg, T. Bergholt, L Eriksen, A. M. Hvas, "Cobalamin status during normal pregnancy and postpartum: a longitudinal study comprising 406 Danish women", European Journal of Haematology, vol. 76, pp. 512-515, 2006.

[28] Waterstone $\mathrm{M}$ et al (2001). Incidence and predictors of severe obstetric morbidity: case control study. BMJ. 2001; 322: 108994.

[29] T. Bergholt, J. K. Stenderup, A. Vedsted-Jakobsen, P. Helm, C. Lenstrup, "Intraoperative surgical complication during cesarean section: an observational study of the incidence and risk factors", Acta Obstet. Gynecol. Scand, vol. 82, pp. 251-256, 2003. 